\title{
Dynamic Mechanical Properties of Oxide Films Formed on Metallic Surfaces as Measured Using a Tribological Approach at High Temperature
}

\author{
Yoshinori Isomoto Oka and Toshinori Tsumura \\ Department of Chemical Engineering, Hiroshima University, Kagamiyama, Higashi-Hiroshima 739-8527, Japan \\ Correspondence should be addressed to Yoshinori Isomoto Oka, iyoshi@hiroshima-u.ac.jp
}

Received 26 July 2011; Accepted 20 August 2011

Academic Editor: J. Paulo Davim

Copyright ( $) 2011$ Y. I. Oka and T. Tsumura. This is an open access article distributed under the Creative Commons Attribution License, which permits unrestricted use, distribution, and reproduction in any medium, provided the original work is properly cited.

The surface degradation of metals in boiler tubes and turbines in high-temperature corrosive environments causes severe problems in fuel combustion power plant systems. High-temperature resistant materials have been recently developed using a thermal barrier coating (TBC) and high-chromium alloys. Oxide films or coatings formed on metal surfaces at high temperatures can sometimes decrease the corrosion rate. However, the damage to the material is often accelerated by the mechanical removal of corrosion products from the material surface. It is therefore very important to investigate the mechanical and adhesive properties of the oxide films or coatings on metal surfaces used in high-temperature environments. This paper introduces a tribological method that uses a single spherical projectile impact at high temperature to measure the mechanical and adhesive properties of oxide films formed on various metal surfaces. Impact tests were performed on the surfaces of oxide films after their growth in a hightemperature furnace, and the deformed or fractured surfaces were observed in order to measure the mechanical and adhesive properties. The mechanical and adhesive properties of an elastic modulus, fracture, and exfoliation stresses were measured using the impact method, and the results depended on the type of metal oxide films and on the high-temperature environment.

\section{Introduction}

Plant component materials such as energy conservation turbine blades operated at high temperatures suffer severe damage from mechanical and corrosive attacks. Many researchers have investigated the development of thermaland corrosion-resistant materials and the behaviour of these materials during high-temperature corrosive activity [1-4]. It is well known that once oxide films have formed on a metal surface, they form diffusion barriers to oxygen, which decreases the corrosion rate. However, damage to materials is accelerated by the mechanical removal of oxide films formed on the material surface, which can happen during routine maintenance such as cleaning. Few investigations into the acceleration mechanisms have been reported $[5,6]$. The development of a TBC and high-temperature resistant alloys possibly prevent plant degradations caused by hightemperature corrosion. It is very important to investigate the mechanical properties of the coating layers of metal surfaces, which can have an effect on the interface between the surface layer and the substrate. A practical high-temperature environment is required for testing, because of the different properties of the surfaces as the temperature environment changes. Few studies have focused on these properties at high temperature [7], although some research papers have focused on the mechanical properties of oxide films at room temperature $[8,9]$. It is also very important to investigate the dynamic mechanical and adhesive properties of these materials in high-temperature environments.

For the present study, we used an impact method to measure the dynamic mechanical properties of oxide films formed on the surfaces of mild steel, titanium, and its alloy $[10,11]$, as examples of practical plant component materials. In this paper, we compare and discuss the mechanical and adhesive properties of oxide films on various metallic materials in high-temperature corrosive environments, 
elucidating the validity of the impact method experimentally. The different high-temperature corrosive environments were selected to change the mechanical and adhesive properties of the oxide films. Equations and assumptions based on the mechanics of the materials were used to obtain the dynamic mechanical and adhesive properties of the oxide films according to the impact of a single spherical projectile and the deformation and fracture phenomena of the oxide films around the impact craters.

\section{Experimental Procedures}

The experimental setup included a simple furnace with a gas feeder, which is schematically shown in Figure 1. The furnace was composed of a ceramic tube, hot coils, a refractory, and a flask for feeding different types of corrosive gases. A block specimen was placed in the middle of the furnace in a hightemperature environment. Single particle impact tests on block specimens $(45 \times 45 \times 100 \mathrm{~mm}$ or $\phi 30 \times 30 \mathrm{~mm})$ in hightemperature corrosive environments were conducted with a compact gas gun, which is schematically shown in Figure 1. Glass beads 2, 3, and $5 \mathrm{~mm}$ in diameter were projected at 50 and $70 \mathrm{~ms}^{-1}$ into specimens that were coated with either a corrosion product or an oxide film. The specimen surfaces at high temperature were observed with a video camera connected to a computer. The spalled and detached areas of the films caused by impact were measured using image processing. The impact craters were observed by scanning electron microscopy (SEM). The contact pressure was calculated as the impact energy divided by the indentation volume, which was geometrically calculated by the crater diameter.

Quasistatic- and dynamic-indentation (Impact) tests of spherical zirconia and hard steel $3 \mathrm{~mm}$ in diameter were performed on metal surfaces at room temperature (R.T.) to obtain compressive strain distributions against the relative indentation distance, $d / a$, as shown in Figure 2. The compressive strain was measured using a strain gauge with a proven distance of $0.5 \mathrm{~mm}$. The gauge was mounted on the specimen surface, $d / 2$, far from the center of the indentation, with a different indentation ratio, $a / D$. Compressive strain distributions were needed to determine the strain when the oxide films formed on the metal surface were fractured or cracked by the arbitrary testing stress.

Commercial mild steel, pure titanium and Ti-6Al-4 V (titanium alloy), and pure nickel were prepared for the present study. The high-temperature corrosive environment included wet air, water vapor, and water vapor with hydrogen chloride at 0.5 and 10 vol\% from the flask as the average volume percentages during the tests. The tested temperatures were held constant at 873 and $973 \mathrm{~K}$ before and after the single-particle impact tests.

\section{Results}

3.1. Single-Particle Impact Tests at High Temperature. Figure 3 shows the impact craters on the films formed on the mild steel in various high-temperature corrosive environments at $873 \mathrm{~K}$. The upper photographs were taken

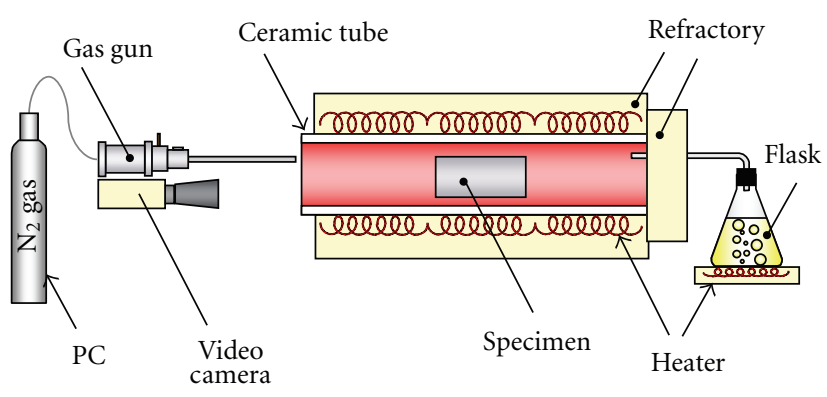

Figure 1: Schematic illustration of furnace and a gas gun.

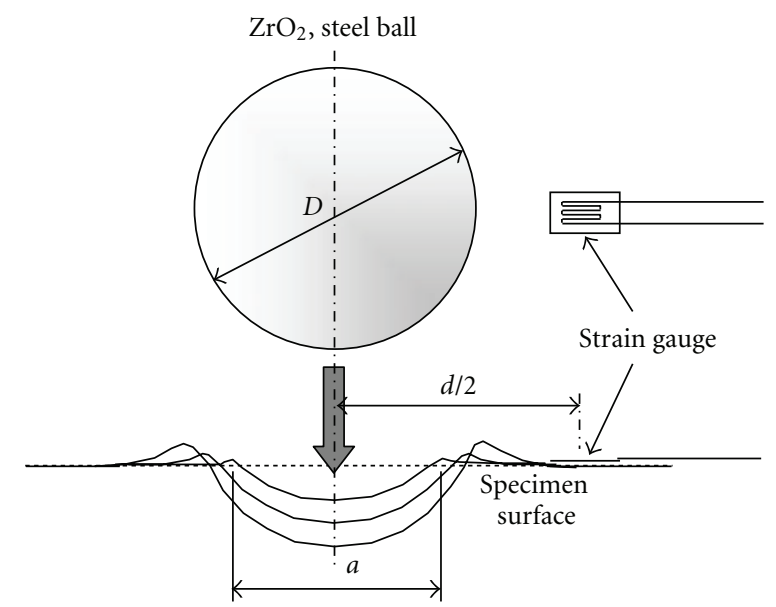

FIGURE 2: Schematic illustration of measuring compressive strains during an indentation process.

just after the impact of a glass ball $3 \mathrm{~mm}$ in diameter at $70 \mathrm{~ms}^{-1}$ when the film thickness was about $35 \mu \mathrm{m}$ (duration time of a few hours). The lower photographs were taken about 15 hours after the impact. The narrowly spalled areas (bright) appear at the crater rim in the upper photographs, and the wide circle areas are accompanied by radial cracks around the impact crater in the lower photographs, as shown in Figures 3-5. The size of the 2 areas changed not only with the corrosive environment but also with the conditions of particle diameter, impact velocity, and film thickness. The films formed at $873 \mathrm{~K}$ were wustite, magnetite, and hematite from a steel substrate. The apparent density of the oxide films decreased with the corrosiveness of the high-temperature environments. The oxide films formed in an environment of water vapor, including $10 \mathrm{vol} \% \mathrm{HCl}$, had a rough surface and relatively low apparent density.

Figures 4 and 5 show the observations of similar impact craters for the pure titanium and titanium alloy in the same environments at $973 \mathrm{~K}$, as shown in Figure 2. The upper photographs were taken just after the impact of a glass ball $5 \mathrm{~mm}$ in diameter at 50 or $70 \mathrm{~ms}^{-1}$ when the thickness of the oxide film was about $10 \mu \mathrm{m}$. The lower photographs were taken about 10 hours after impact. Radial cracks around the impact crater could not be observed on the oxide film of either the titanium or its alloy. The oxide film formed on 


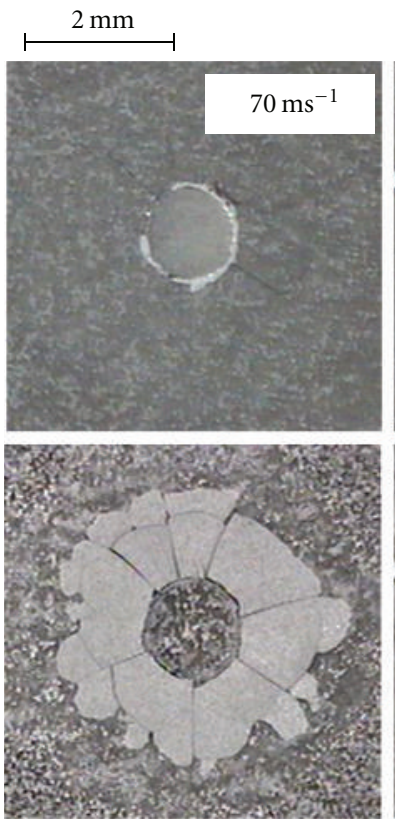

Wet air
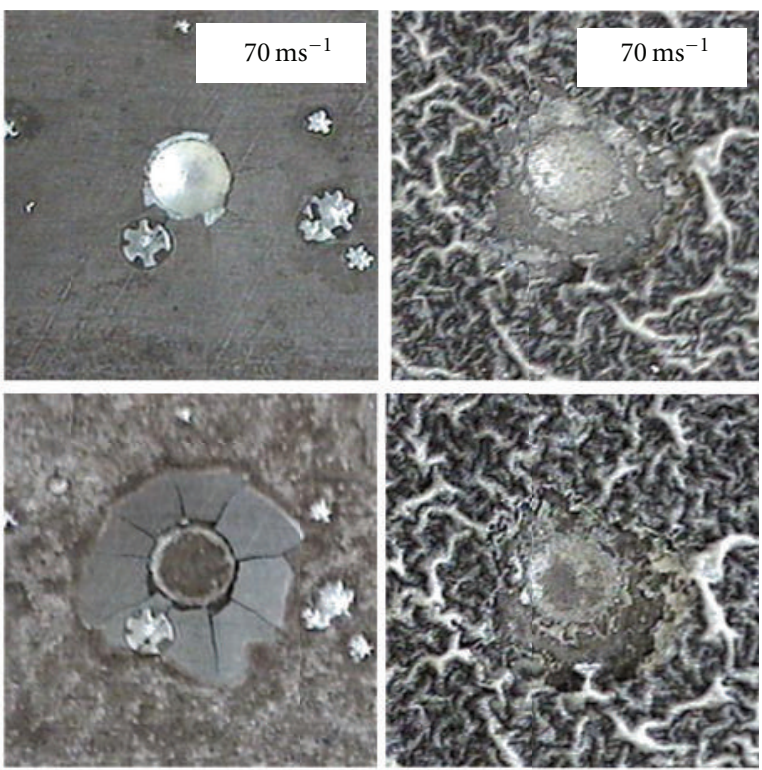

$0.5 \mathrm{vol} \% \mathrm{HCl}$

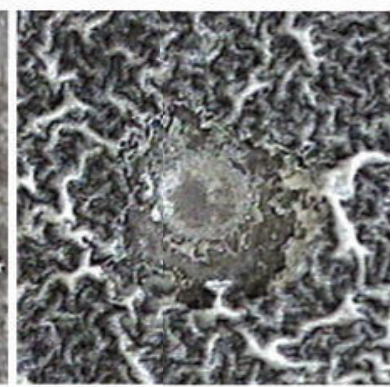

$10 \mathrm{vol} \% \mathrm{HCl}$

FIGURE 3: Appearances of oxide films formed on mild steel after the impact of a glass bead at $873 \mathrm{~K}$ (upper photographs) and at about 15 hours after the impact (lower photographs).

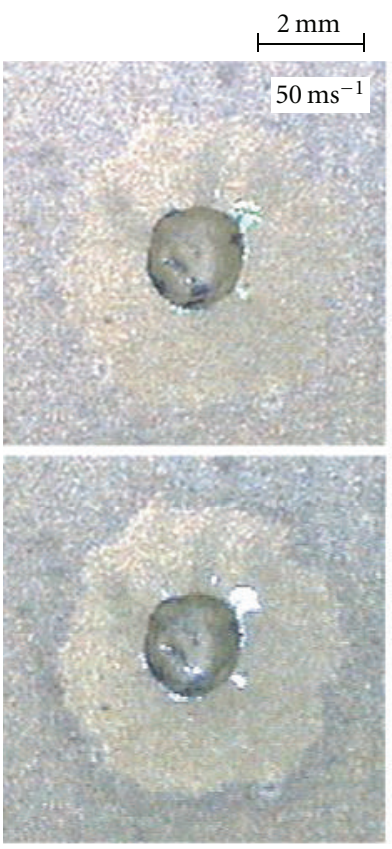

Air

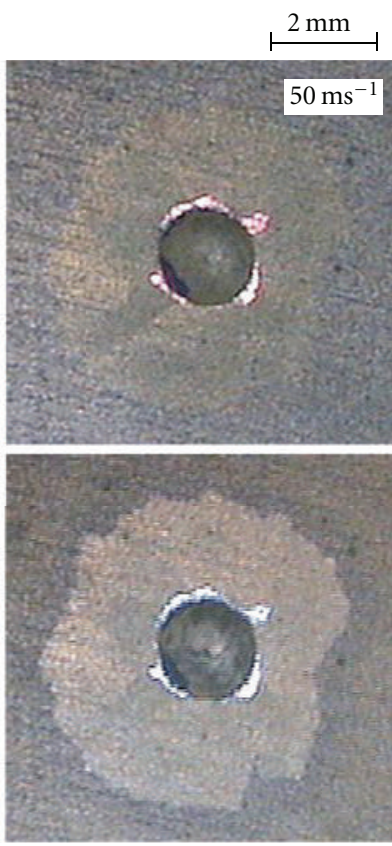

$0.5 \mathrm{vol} \% \mathrm{HCl}$

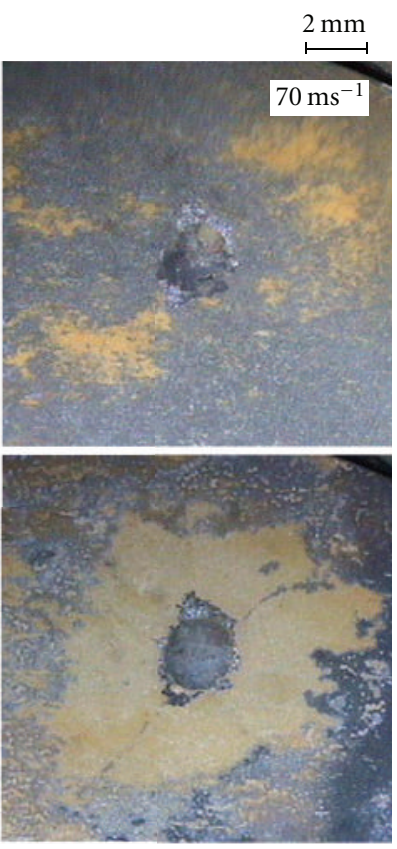

$10 \mathrm{vol} \% \mathrm{HCl}$

FIGURE 4: Appearances of oxide films formed on Ti after the impact of a glass bead at $973 \mathrm{~K}$ (upper photographs) and at about 10 hours after the impact (lower photographs).

titanium and its alloy in a high-temperature environment was rutile, but the density of the titanium oxide was not measured because of the thin films.

Figure 6 shows the SEM observations of the impact craters on the nickel oxide film impacted by a glass ball with a diameter of $2 \mathrm{~mm}$ at $70 \mathrm{~ms}^{-1}$ in air at $973 \mathrm{~K}$ and
R.T. The film thickness was approximately 16 or $7 \mu \mathrm{m}$. The spalling of the oxide films was not observed in the nickel specimens. Circumferential cracks were seen in the inside area near the crater rim and radial cracks both inside and around the impact crater extended to a wide area far from the indentation. Remarkably, these cracks were seen in the 

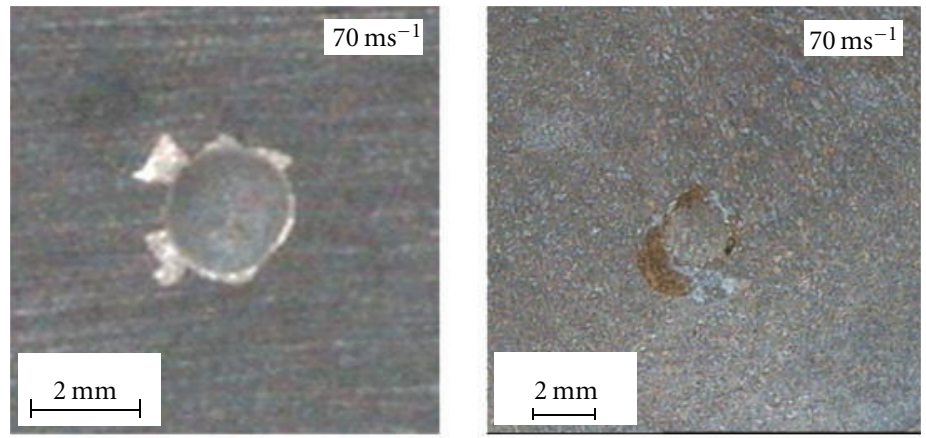

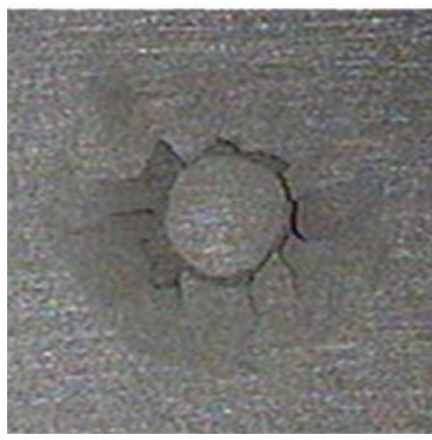

Air

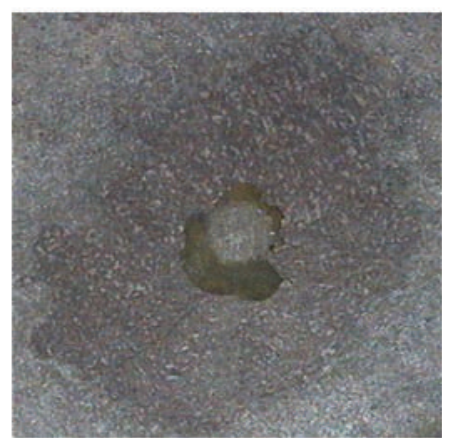

$10 \mathrm{vol} \% \mathrm{HCl}$

FIgURE 5: Appearances of oxide films formed on Ti alloy in various environments at $973 \mathrm{~K}$ (upper photographs) and at about 10 hours after the impact (lower photographs).

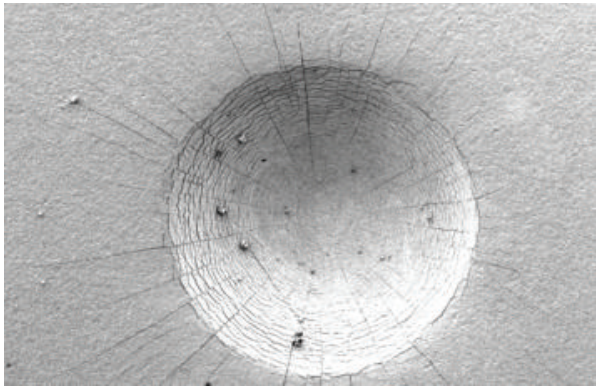

(a)

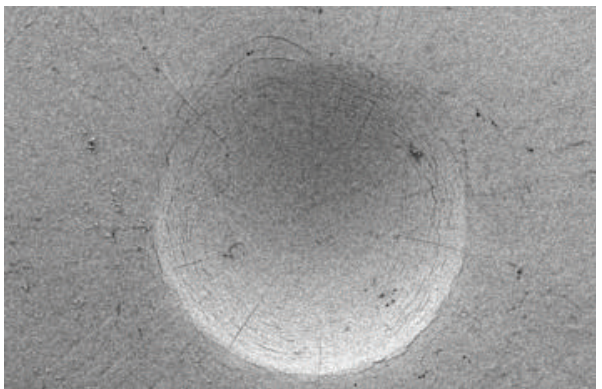

(c)

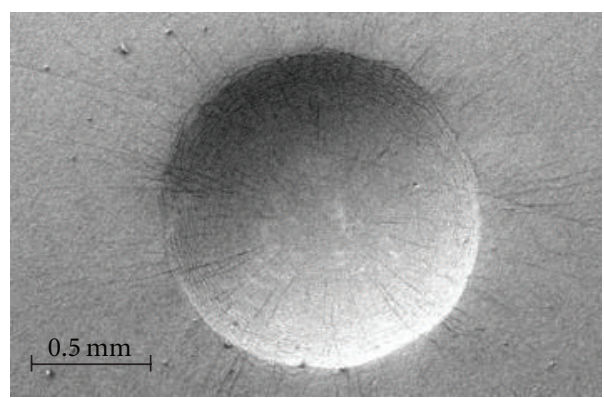

(b)

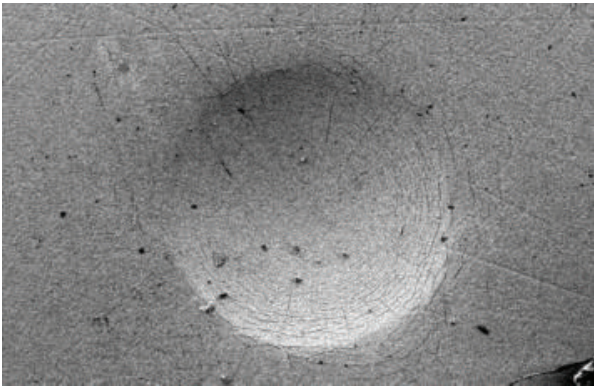

(d)

FIGURE 6: SEM observations of an indentation formed on pure Ni with an oxide film. (a) at $973 \mathrm{~K}$, film thickness $16 \mu \mathrm{m}$ (at air $973 \mathrm{~K}$ ), (b) at $973 \mathrm{~K}$, film thickness $7 \mu \mathrm{m}$ (at air $973 \mathrm{~K}$ ), (c) at R.T., film thickness $16 \mu \mathrm{m}$ (at air $973 \mathrm{~K}$ ) and (d) at R.T. film thickness $7 \mu \mathrm{m}$ (water vapor at $973 \mathrm{~K})$. 


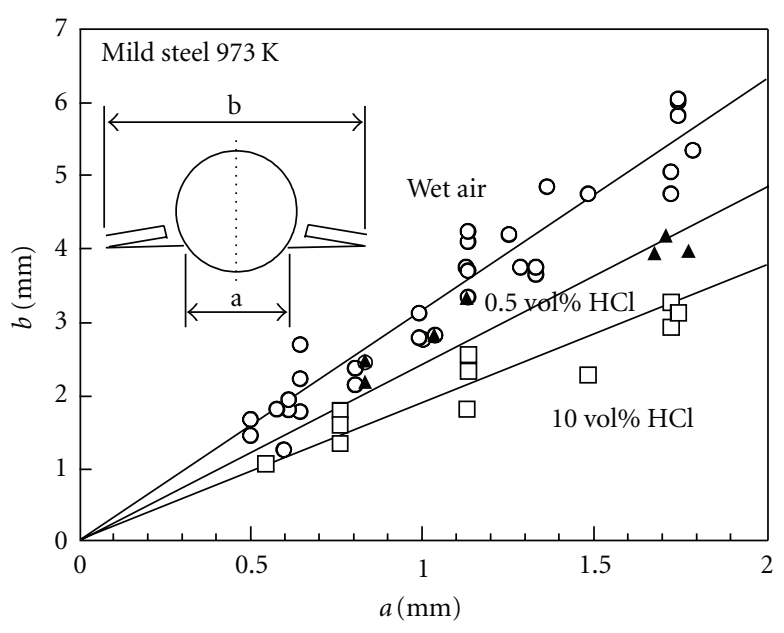

(a)

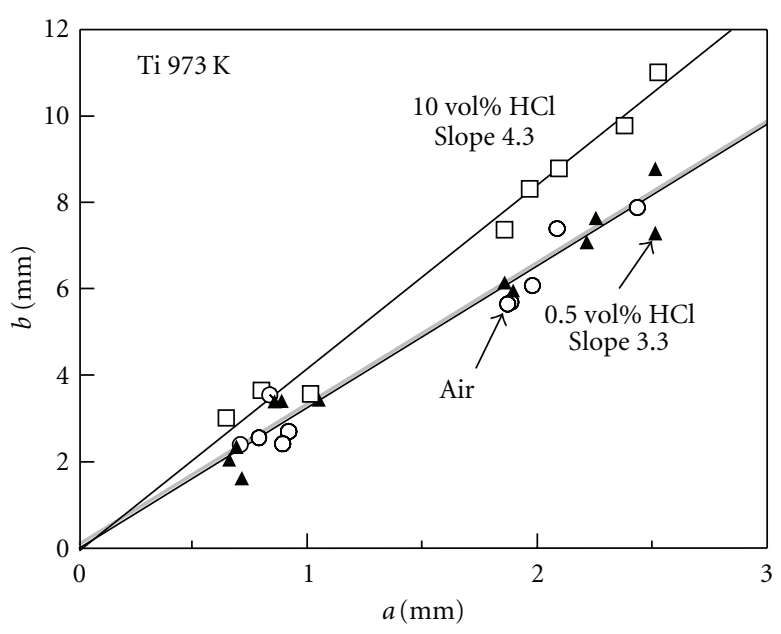

(b)

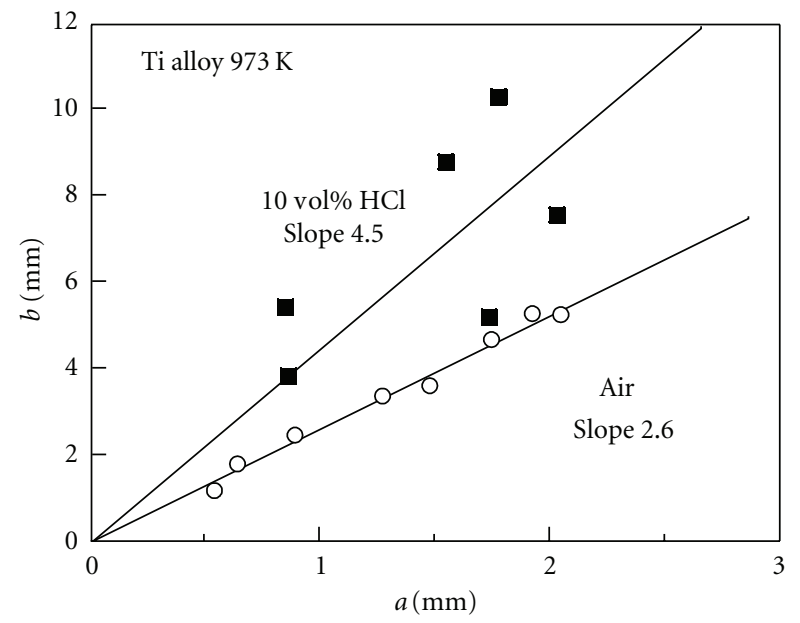

(c)

FIGURE 7: Relations between the diameters of indentation and of detached area in various high temperature corrosive environments.

impact crater not only at $973 \mathrm{~K}$ but a few were also seen at R.T. The maximal length of terminated radial cracks was longer at impact at $973 \mathrm{~K}$ than that at R.T. Minimal and maximal crack diameters were recognized.

Figure 7 shows the relationship between a crater diameter $a$ and an equivalent diameter $b$ which is defined as the square root of the entire detached area, including the indentation area, divided by $\pi / 4$, for mild steel (a), titanium (b), and its alloy (c), according to Figures 3-5. In each environment independent of the different size of the craters with different impact velocities, particle diameter, and film thickness, $b$ correlated to $a$. The slope of the linear curve in wet air was higher than that in the other environments for mild steel. On the contrary, the slope of the linear curve in water vapor with $10 \mathrm{vol} \% \mathrm{HCl}$ was higher than that in the other environments for titanium and its alloy. The relationships differed among the different types of metals.

In the case of nickel, no detached area of the oxide films could be found, but a few radial cracks were observed from the impact of a projectile at both R.T. and high temperature. Figure 8 shows the relationship between the crater diameter $a$ and the maximal radial crack diameter $b . a$ increased with an increase in the impact velocity, and $b$ roughly correlated to $a$ depending upon the environment, but was independent of the larger size of the crater obtained by the higher impact velocity.

3.2. Compressive Strain Distributions for Various Metals. Figure 9 shows the relationship between the compressive strains and the relative distance, $d / a$, in quasistatic and dynamic indentations for mild steel and titanium. The compressive strain distribution against $d / a$ was nearly the same in the case of any indentation ratios $a / D$, any type of metals, and any of the indentation (quasistatic and dynamic) processes. The compressive strain decreased rapidly from the rim (lip) of the crater. The compressive strains above approximately $0.2 \%$ generally showed a plastic deformation of the substrate metal.

The compressive strain distribution of nickel was different from that of mild steel and titanium, as shown in Figure 10. The compressive strain near the indentation and the tensile strain located far from the indentation was 


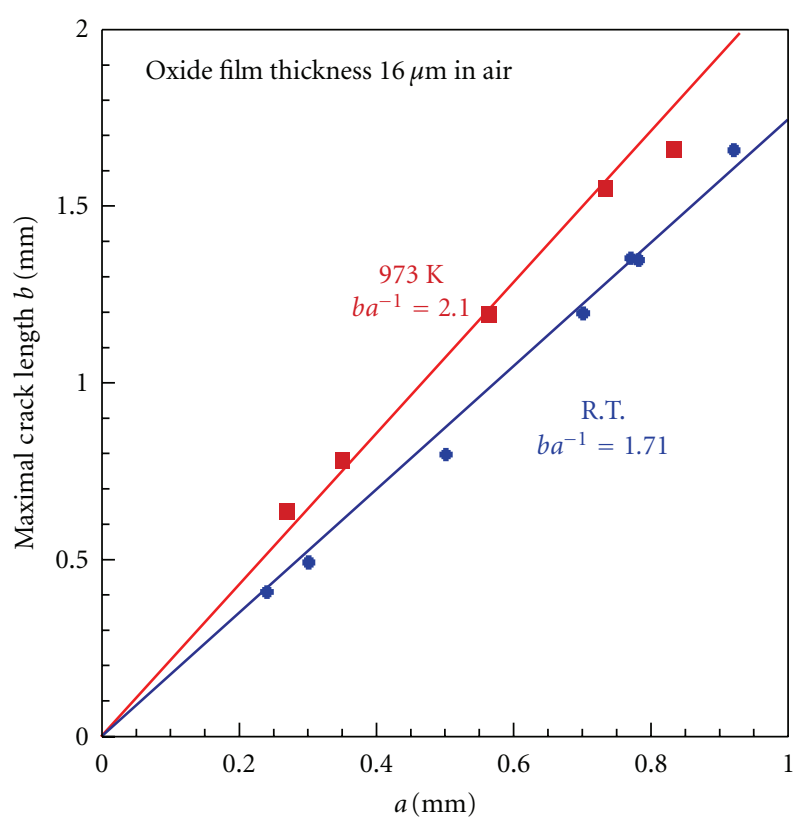

FIGURE 8: Relations between diameter of indentation $a$ and maximal crack length $b$ by the impact at $973 \mathrm{~K}$ and R.T., for nickel oxide films formed at $973 \mathrm{~K}$.

observed. The values of strains generated in the nickel surface were smaller compared with that generated in mild steel and titanium.

\section{Discussion}

4.1. Destruction and Crack Processes of Oxide Films. The impact of a projectile onto metal surfaces with oxide films caused fractures or cracks of oxide films and great plastic deformation of the metal substrate. The two fracture processes were consequently classified by the presence or absence of the exfoliation of oxide films formed on metal surfaces. These processes had different fracture mechanisms of the oxide films.

As shown in Figures 3-5, for mild steel, titanium, and its alloy, the destruction processes of the oxide films consisted of the first fracture at the indented area, the subsequent detaching in a wide area around the impact crater, and the last fracture of the oxide film around the rim of the crater; oxide film growth after the rebound of a projectile is shown in Figures 11(a)-11(f). The projectile impacted the oxide films on the metal surface, and exfoliation occurred with the destruction of the oxide films beneath the projectile. The detached area gradually extended in a radial direction with an increase in the surface strain distribution during the impact of the projectile. The radial extension of the detached area was probably determined at the maximum indentation, and the final spalled area was formed around the rim of the maximum crater. The final spalled area-the tip of the detached oxide films - was fractured upon completion of the forward motion of the projectile. After the rebound of the projectile, it was very interesting that the detached area emphasized the difference in film growth about 15 hours

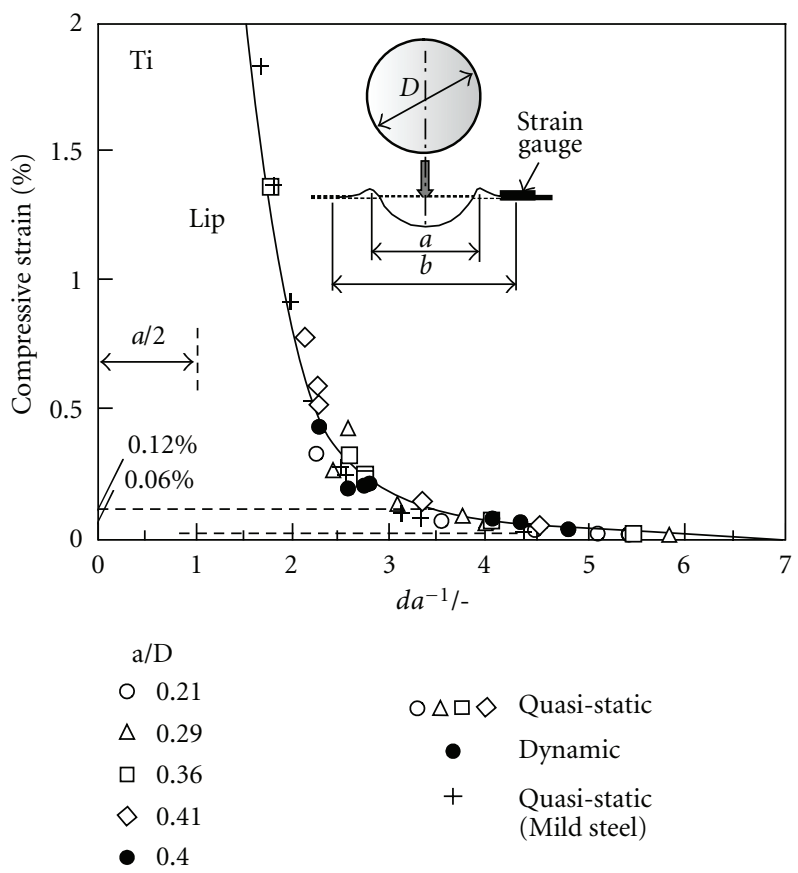

Figure 9: Compressive strain distribution against relative distance $d / a$ in quasistatic and dynamic indentations at R.T. $\bullet \Delta \square \diamond$ for Ti, + for mild steel.

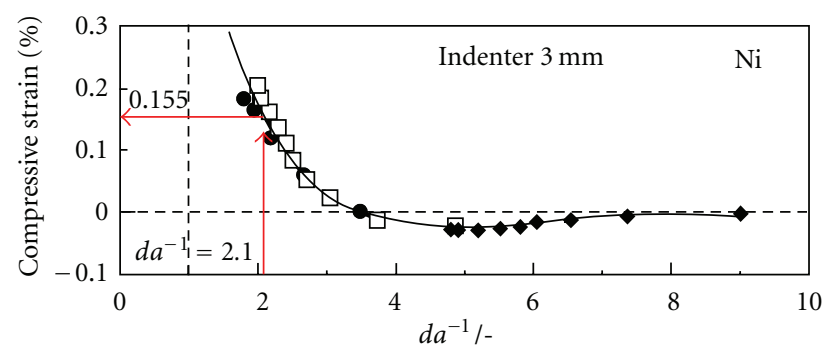

FIGURE 10: Compressive strain distribution against relative distance $d / a$ in quasistatic for pure nickel.

after impact, a phenomenon which could not be observed immediately following the impact of the projectile. The oxide film at the detached area ceased growing and was pushed up by the growth of new oxide film underneath. Once it was detached, the old oxide film maintained its smooth surface. The outer oxide film far from the detached film continued to roughen with growth. Taking into account the exfoliation processes, it can be assumed that the oxide film is detached by the shear stress accompanied by the surface strain and that the detached film from the surface is thereafter spalled by the compressive stress from the projectile.

The fracture process of nickel oxide films on pure nickel is estimated in Figures 12(a)-12(d). Exfoliation did not occur with the nickel oxide films due to superior adhesion between the oxide films and the metal surface and the small amount of surface strain. The radial cracks initiated in a small area of the indentation during the impact of the projectile, developed in an outer region, and terminated to a larger area than the 


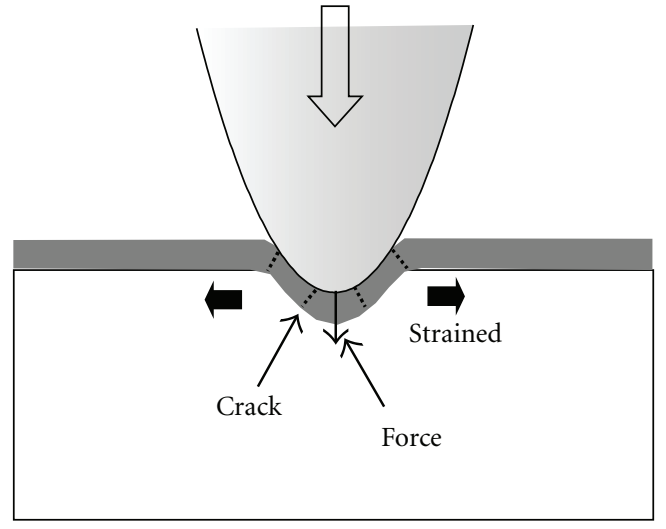

(a)

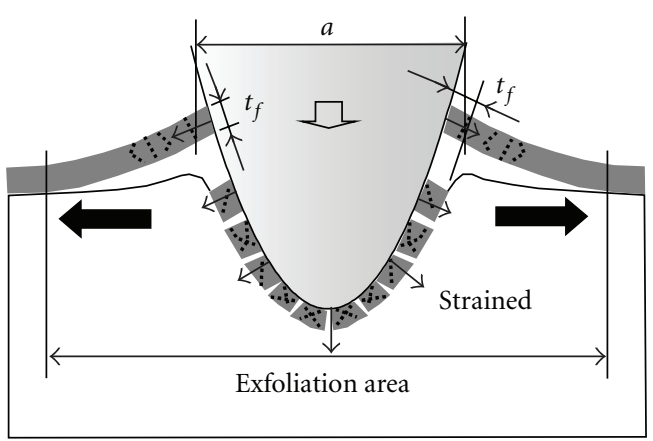

(c)

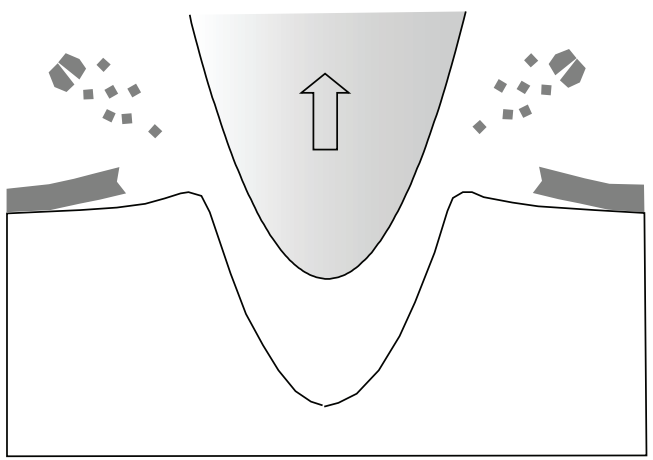

(e)

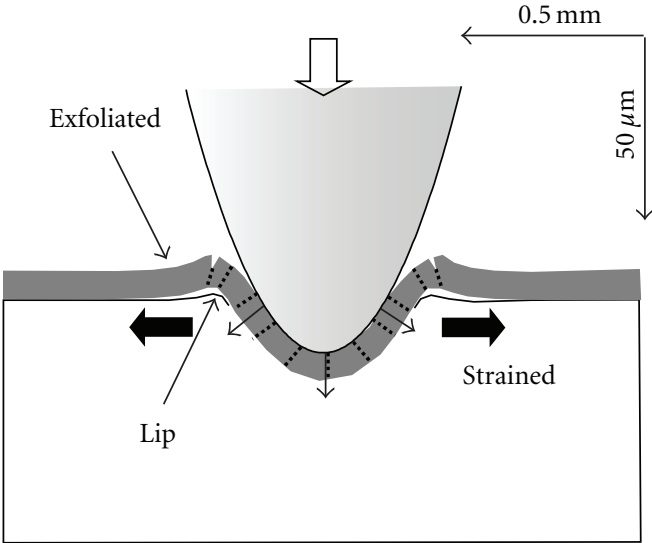

(b)

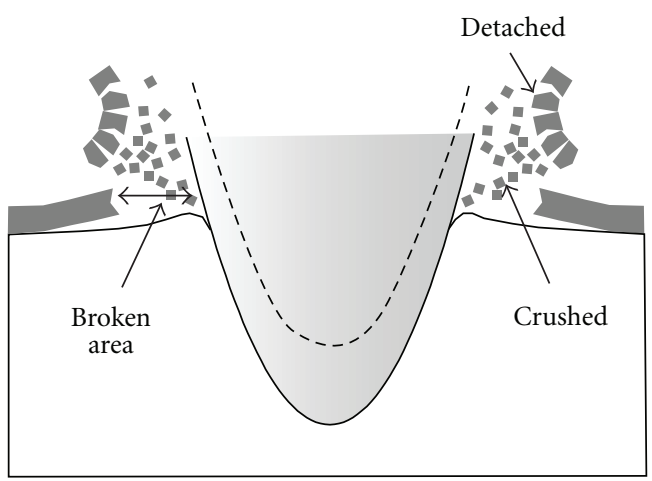

(d)

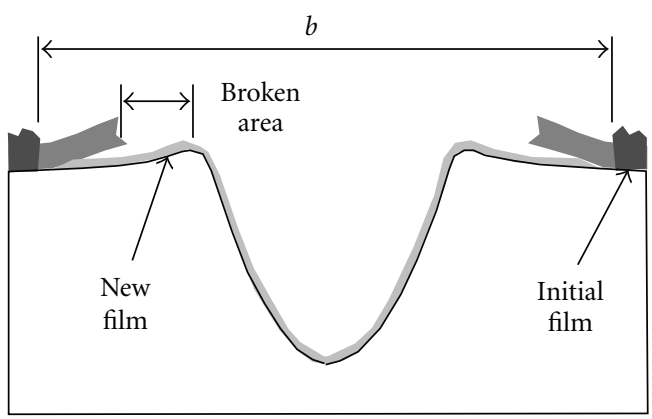

(f)

FIGURE 11: Exfoliation and fracture process of oxide films by the impact of a glass ball at a high-temperature environment.

indentation. The first fracture or cracking occurred in the small indentation and showed the fracture stress of the nickel oxide film. It is also postulated that the cracks of oxide films extend by circumferential tensile stress or strain generated on the nickel surface at the last stage and that the crack length in the outer region shows the minimal strain of the cracked nickel oxide film.

4.2. Equations for Mechanical Properties of Oxide Films. From the observations of the foregoing fracture and exfoliation processes during the dynamic indentation of a projectile, we made some assumptions to estimate the exfoliation stress, $\sigma_{a}$, fracture stress, $\sigma_{f}$, and elastic modulus, $E_{f}$, of oxide films under the dynamic indentation experienced in hightemperature corrosive environments.

We postulated that the exfoliation stress was defined by the surface stress, $\sigma_{a}$, generated in the metal surface, then could be roughly estimated by the surface strain, $\varepsilon$, measured in the present experiment and by the stress-strain curves at high temperature, as follows:

$\sigma_{a}=K \varepsilon^{0.3}(K=450 \mathrm{MPa}$ for mild steel $)$,

$\sigma_{a}=E \varepsilon(E=20 \mathrm{GPa}$, stress gradient in the plastic strain region $50 \mathrm{MPa}$ for titanium and its alloy [8]). 


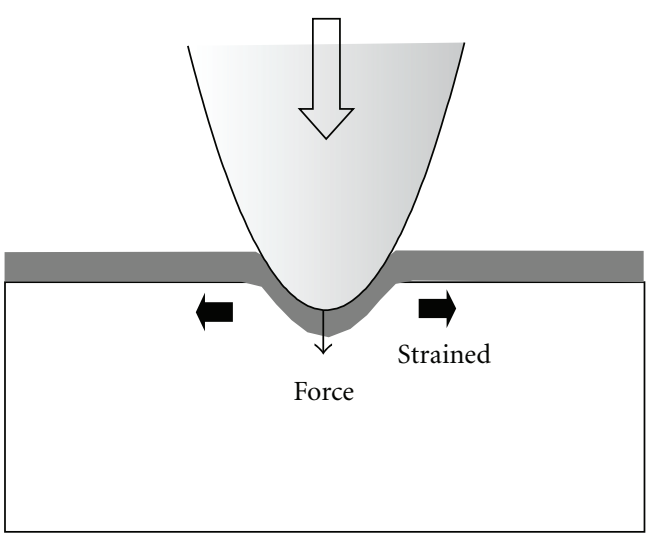

(a)

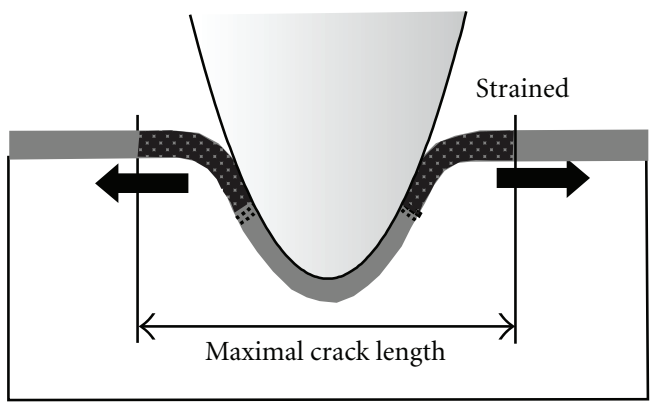

(c)

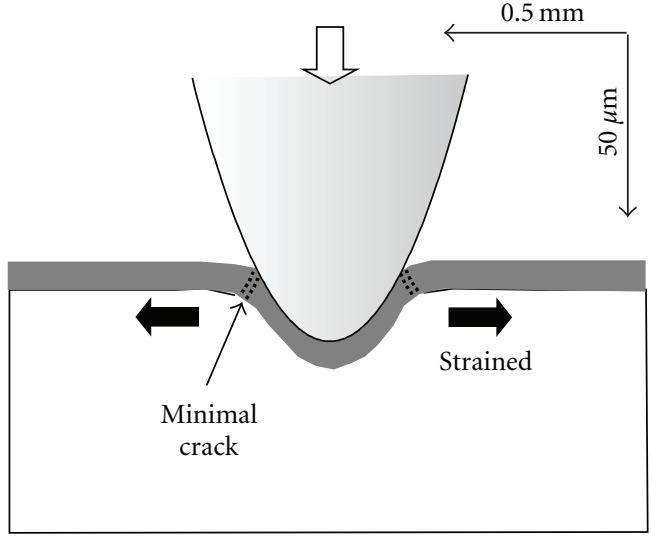

(b)

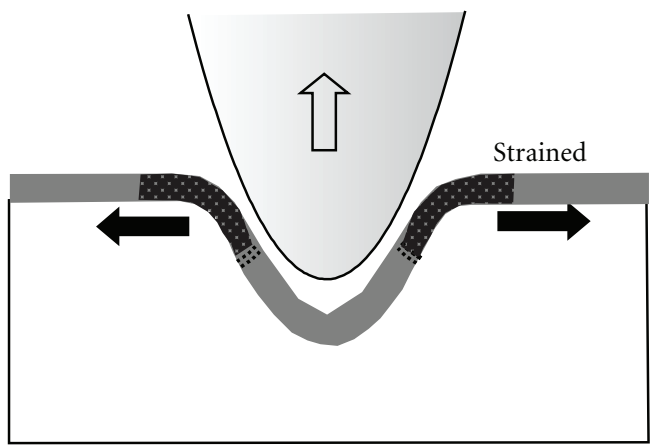

(d)

Figure 12: Cracking process of oxide films formed on a Ni specimen by the impact of a glass ball.

TABLE 1: Mechanical properties of oxide films formed on metal surfaces.

\begin{tabular}{|c|c|c|c|c|c|}
\hline & $\varepsilon(\%)$ & $\varepsilon_{f}(\%)$ & $\sigma_{f}(\mathrm{MPa})$ & $E_{f}(\mathrm{GPa})$ & $\sigma_{a}(\mathrm{MPa})$ \\
\hline \multicolumn{6}{|l|}{ Mild steel (873 K) } \\
\hline Wet air & 0.5 & 0.25 & 530 & 213 & 74.6 \\
\hline 0.5 vol $\%$ HCI & 1.4 & 0.7 & 220 & 31.9 & 102 \\
\hline 10 vol $\% \mathrm{HCI}$ & 0.7 & 0.34 & 37 & 1.09 & 162 \\
\hline \multicolumn{6}{|l|}{ Titanium (973 K) } \\
\hline Air & 0.24 & 0.12 & 44.3 & 36.9 & 24 \\
\hline 0.5 vol $\%$ HCI & 0.24 & 0.12 & 44.3 & 36.9 & 24 \\
\hline 10 vol $\%$ HCI & 0.12 & 0.06 & 23.3 & 38.8 & 12 \\
\hline \multicolumn{6}{|c|}{ Titanium alloy (973 K) } \\
\hline Air & 0.60 & 0.30 & 145 & 48.3 & 45 \\
\hline 10 vol $\% \mathrm{HCI}$ & 0.10 & 0.05 & 27.0 & 54.0 & 10 \\
\hline \multicolumn{6}{|l|}{ Nickel } \\
\hline Air $(973 \mathrm{~K})$ & 0.155 & 0.078 & 243 & 157 & - \\
\hline Air (R.T.) & 0.258 & 0.129 & 568 & 220 & - \\
\hline
\end{tabular}

The surface strain, $\varepsilon$, is also considered to be the shear strain, $\gamma_{f}$, when the oxide film is terminally exfoliated during impact. The exfoliation stresses of the oxide films for mild steel, titanium, and its alloy were obtained by the measured strain, $\varepsilon$, in (1).

Upon contact with the projectile, the oxide film first fractured then exfoliated with the progress of the surface strain accompanied by the formation of an indentation, and finally the oxide film fractured or broke around the rim of the indentation, as shown in Figures 3-5. The final fracture volume of the rim was connected to the partial impact energy of the projectile as it acted on the contact area of the oxide film. The force, $F$, of the projectile, as shown in (2), applies to the oxide film to be fractured and is assumed to be equal to the product of the average contact pressure, $P[12,13]$, and the contact area, $A$, of the films. The average contact pressure 


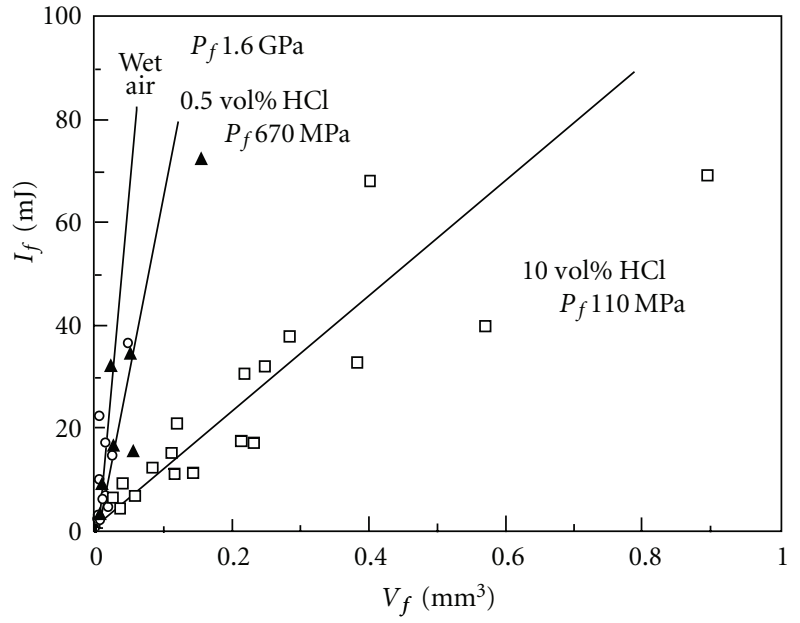

(a)

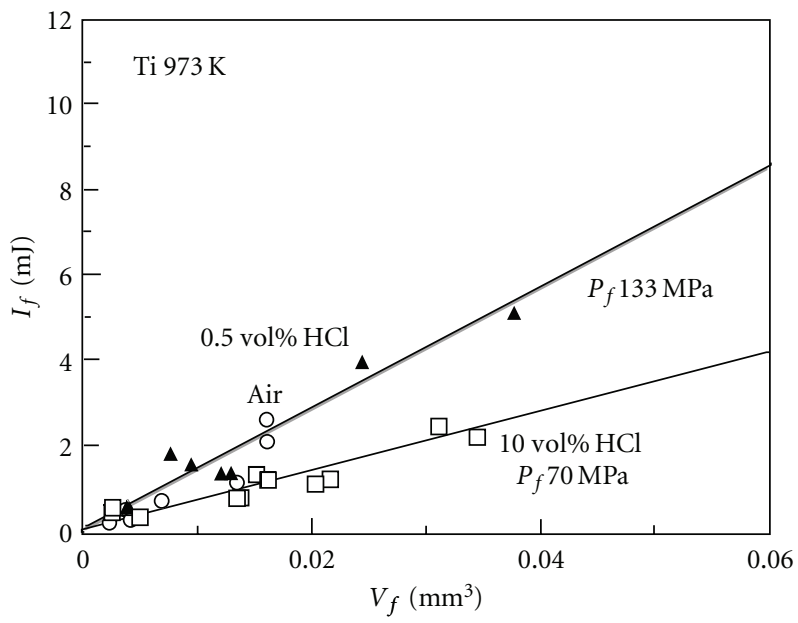

(b)

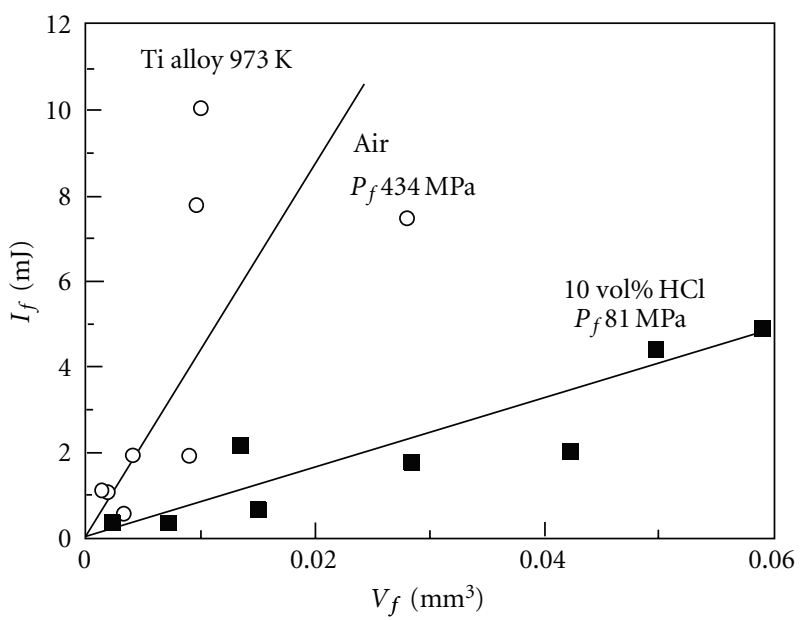

(c)

FIGURE 13: Relations between fracture energy and volume for (a) mild steel, (b) Ti, and (c) Ti alloy in various corrosive environments.

is the impact energy, $I_{\mathrm{Ep}}$, divided by the indentation volume, $V$ :

$$
F=P A=\left(\frac{I_{\mathrm{Ep}}}{V}\right)\left(\pi a t_{f}\right)
$$

where $a$ is the crater diameter, as described previously, and $t_{f}$ is the thickness of the oxide film. If it is assumed that the intruded distance at the final fracture of the oxide film during the indentation is the same as the thickness of the oxide film, $t_{f}$, the pressure, $P_{f}$ (unit of $\mathrm{Pa}$ ), which is applied for the fracture of the oxide film, is the fracture energy, $I_{f}\left(I_{f}=F t_{f}\right)$, divided by the fracture volume, $V_{f}$, as follows:

$$
P_{f}=\frac{I_{f}}{V_{f}}=\frac{F t_{f}}{V_{f}} .
$$

In the case of the nonspalled nickel oxide film, it is assumed that the contact force is separate from the force applied to the fracture of the oxide film and the force applied to the substrate indentation. As the nickel oxide film was thin, the contact pressure, $P$, was separate from the $P_{f}$ of the film and the $P_{s}$ of the substrate. If so, then $P_{f}$ is obtained as follows:

$$
P_{f}=P-P_{s}
$$

Tabor regards yield stress as making up one third of the surface hardness [14], which is equivalent to contact pressure, and, therefore, the compressive fracture stress of the oxide films, $\sigma_{f}$, is then

$$
\sigma_{f}=\frac{P_{f}}{3} .
$$

As metallic oxide films are normally brittle, the elastic modulus of the metallic oxide $E_{f}$ should then be calculated as follows:

$$
E_{f}=\frac{\sigma_{f}}{\varepsilon_{f}}\left(\varepsilon_{f}=\frac{\gamma_{f}}{2}=\frac{\varepsilon}{2}\right),
$$

where $\varepsilon$ is the experimentally obtained compressive strain. The fracture stress and elastic modulus of the oxide films for mild steel, titanium, and its alloy are obtained through (2)(6). 


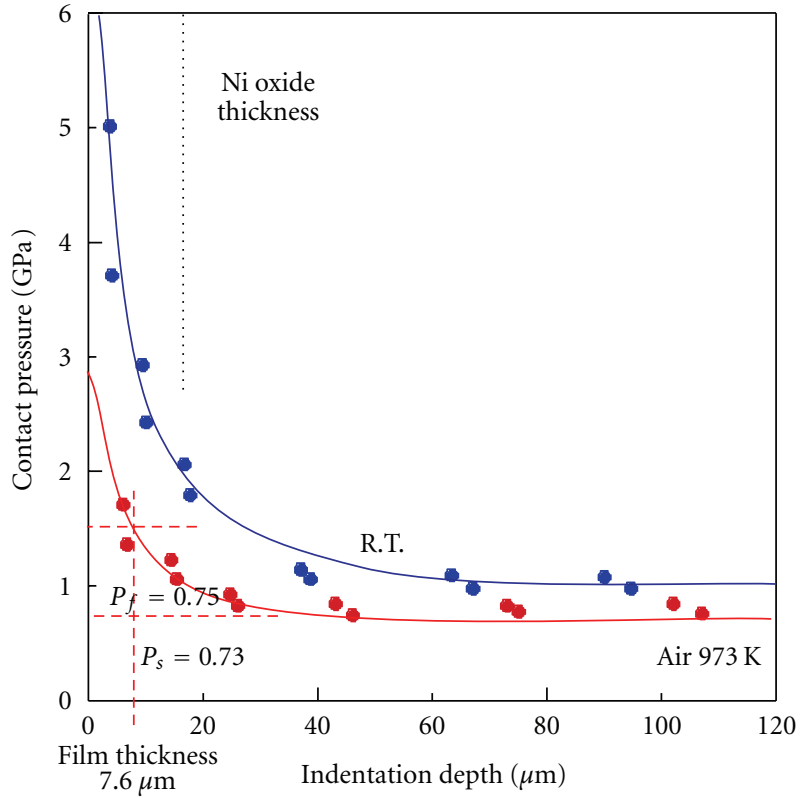

FIgURE 14: Contact pressure versus indentation depth curves for nickel specimens at R.T. and $973 \mathrm{~K}$.

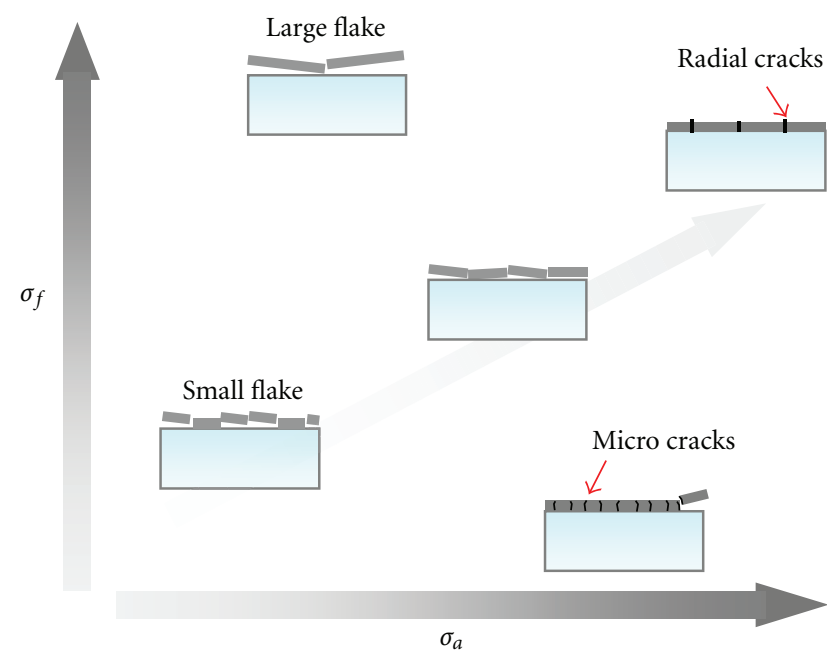

FIGURE 15: Failure model of oxide films formed on metal surfaces during dynamic indentation process.

Taking into account the initially cracked and the terminally cracked length in the crack process of the nickel oxide film, as shown in Figures 6, 8, and 12, the fracture stress, $\sigma_{f}$, of the nickel oxide film was estimated using (5), and $P_{f}$ is regarded as the contact pressure when the was first crack initiated. The elastic modulus of the nickel oxide film was obtained using (6) - this is also called the compressive strain, which is the last process of the crack formation.

4.3. Determination of the Surface Strain as Measured by the Fracture or Crack Process. As shown in Figure 7, $b$ was roughly related to $a$ in each environment, independent of the different size of the craters ( $a$ differed) from the different impact velocities, particle diameters, and film thicknesses, for the 3 types of metals. The slopes in these figures were regarded as constant, and the constant ratios of $b$ to $a$ depended on the environment. However, the compressive strain depends on the relative distance of $d / a$ from the center of the indentation irrespective of the indentation ratio, $a / D$, the type of material, or the indentation process, as shown in Figure 9. This means that the compressive strain distribution is valid for the same metals at high temperature.Therefore, it is assumed that the compressive strain, when the oxide film is exfoliated, can be obtained from Figures 7 and 9 by substituting $b$ for $d$. The surface strains in the 3 metals and corrosive environments are summarized in Table 1. These strains depended upon the various oxide films formed in the corrosive environments. The surface strain of the oxide film for mild steel in water vapor containing $10 \mathrm{vol} \%$ of hydrogen chloride was high because of a low apparent density of the iron oxide and microcracks due to a high growth rate of the oxide film caused by the hydrogen chloride.

However, the maximal crack length (as an equivalent diameter of $b$ ) of the nickel oxide film agreed well with the diameter of the indentation, $a$, in each environment. The ratio of $b$ to $a$ was constant depending upon the environment. It is interesting that the strain measured around the indentation was tensile for the nickel specimen. The tensile strain when nickel oxide film is cracked can be obtained from Figures 8 and 10 and is listed in Table 1 .

4.4. Mechanical Properties of Oxide Films during the Dynamic Indentation Process. The exfoliation stresses, $\sigma_{a}$, which are estimated from the surface strains obtained in these experiments using (1), are listed in Table 1. The values for the exfoliation stress of iron oxide films increased with the corrosiveness of the environment and were larger than those of titanium oxide (rutile) films. The exfoliation stress probably depends upon the apparent density and microstructure of oxide film. For an example of thermal stress, the difference in the expansion coefficient, $3.5 \times 10^{-6}$, strain per Kelvin between mild steel and iron oxide in wet air is derived by an easy exfoliation of iron oxide films with 100 degrees of temperature difference $\Delta T$. The expected expansion coefficients, $\alpha_{1}$ and $\alpha_{2}$, of titanium, $8.4 \times 10^{-6}$, and titanium oxide, $7 \times 10^{-6}$, respectively, were estimated along with the temperature difference of $465 \mathrm{~K}$ : by $\sigma_{a}, E_{f}$ from $\Delta T=$ $\sigma_{a} /\left(E_{f}\left(\alpha_{1}-\alpha_{2}\right)\right.$ when the titanium oxide film was exfoliated by thermal stress. These results were probably reasonable when discussing the exfoliation stress of the oxide films.

The relationships between the fracture volume, $V_{f}$, and the fracture energy, $I_{f}$, of the oxide films for the 3 metals of mild steel, titanium and its alloy are shown in Figure 13. Although the data were scattered, the relationships were generally good and the slopes were different depending upon the type of the corrosive environment. The fracture energy for mild steel oxide films was larger than that for titanium, and its alloy, as the oxide films formed on the steel surface were thick during similar oxidation periods. The slopes show the ratio of $I_{f}$ to $V_{f}$ as $P_{f}$. However, the fracture pressure for 
the nickel oxide film could not be obtained as with the mild steel and titanium. Figure 14 shows the contact pressure distributions for nickel during the spherical impact at $973 \mathrm{~K}$ and R.T. With minimal contact pressure, $P$, when a radial crack was initiated during impact, the fracture pressure, $P_{f}$, was obtained as shown in Figure 15. The values of $\sigma_{f}$ modified by (5) for the various oxide films are summarized in Table 1. The apparent densities of the oxide films formed in the 2 corrosive environments were low because of the high rates of oxidation accelerated by the corrosive environments including hydrogen chloride. The values for the fracture stress of the titanium oxide film were lower than those of the mild steel. The strength of the oxide films depended upon the oxidation rate and was affected by the environment and type of metal.

The values for $E_{f}$ of the various oxide films are summarized in Table 1 and were obtained from $\sigma_{f}$ and $\varepsilon_{f}$ in (6). In wet air, the $E_{f}$ values for the oxide films of mild steel and nickel were higher, and lower for mild steel, titanium, and its alloy in the corrosive environments. The mechanical properties probably reflected the apparent density, film growth rate, and inherent physical and chemical properties of the oxide films. In the present study, these mechanical properties were very dynamic in the spherical indentation process.

4.5. Failure Model of Oxide Films during the Dynamic Indentation Process. The foregoing results obtained from the dynamic indentation tests for various metals under various high-temperature environments suggest a failure model for the oxide films formed on a metal surface during a dynamic indentation process, as shown in Figure 15. The failure model of the oxide films depends upon the relative intensity between the exfoliation and fracture stresses. When the exfoliation stress is equivalent to the fracture stress, the fractured flakes of oxide film are proportional, but smaller exfoliation stresses probably shorten the sizes of the fracture flakes. A larger fracture stress tends to enlarge the size of the fracture flakes. On the contrary, a relatively larger exfoliation stress can cause microcracks in the oxide film and prevent apparent exfoliation, as observed in the iron oxide films in high-temperature corrosive environments. The exfoliation stresses of the iron and titanium oxide films measured in the present study were lower than the strength of the metals, so the oxide films could be easily exfoliated by an external force or stress such as particle impact.

\section{Conclusions}

Single particle impact tests in high-temperature corrosive environments were performed on oxide films formed on metal surfaces in order to obtain the dynamic mechanical properties of the oxide films. The dynamic mechanical properties of fractured stress, exfoliation stress, and the elastic modulus of the oxide films were compared for mild steel, titanium and its alloy, and pure nickel. The results obtained in this study are as follows.

(1) The fracture stress was higher for the oxide films formed on mild steel and nickel in a hightemperature environment of either wet air or dry air than for titanium and its alloy in all high-temperature corrosive environments.

(2) The exfoliation stress of the oxide films was the highest for mild steel under water vapor with $10 \mathrm{vol} \%$ hydrogen chloride at $973 \mathrm{~K}$. However, microcracks occurred on the oxide films of mild steel and produced low values for fracture stress due to the low apparent density of the oxide films formed in hightemperature corrosive environments.

(3) The values for the elastic modulus of the oxide films was high for iron and nickel, for which the fracture stress was also high in high-temperature and both wet-air and dry-air environments, but the values were low for the other oxide films in the high-temperature corrosive environments.

(4) A failure model was proposed for oxide films formed on metal surfaces during a dynamic indentation process.

\section{References}

[1] Y. Ihara, H. Ohgame, K. Sakiyama, and K. Hashimoto, "The corrosion behaviour of iron in hydrogen chloride gas and gas mixtures of hydrogen chloride and oxygen at high temperatures," Corrosion Science, vol. 21, no. 12, pp. 805-817, 1981.

[2] S. Hayashi, M. Fukumoto, S. Maeda, and T. Narita, "The effect of water vapor on oxidation behavior of iron-X $(\mathrm{X}=\mathrm{Al}, \mathrm{Cr}$ or Si) alloys at high temperature," JSCE Journal (Zairyo-toKankyo), vol. 51, no. 3, pp. 115-122, 2002.

[3] Y. Watanabe, Y. Yi, T. Kondo, K. Suzuki, and K. Kano, "Steam oxidation of ferritic heat-resistant steels for ultra supercritical boilers," JSCE Journal (Zairyo-to-Kankyo), vol. 50, no. 2, pp. 50-56, 2001.

[4] C. M. Xu and J. T. Guo, "Effect of nickel aluminide microcrystalline coating on high-temperature oxidation behavior of NiAl-33.5\% Cr-0.5\% Zr alloy," Corrosion, vol. 59, no. 4, pp. 350-355, 2003.

[5] I. G. Wright, V. K. Sethi, and A. J. Markworth, "A generalized description of the simultaneous processes of scale growth by high-temperature oxidation and removal by erosive impact," Wear, vol. 186-187, no. 1, pp. 230-237, 1995.

[6] S. Thavendra, T. Oe, and Y. I. Oka, "An attempt of life assessment of boiler materials under high temperature erosive environments," in Proceedings of the 2nd International Conference on Environment Sensitive Cracking and Corrosion Damage (ESCCD '01), p. 148, Hiroshima, Japan, 2001.

[7] Y. I. Oka, T. Yoshida, Y. Yamada, T. Yasui, and S. Hata, "Evaluation of erosion and fatigue resistance of ion plated chromium nitride applied to turbine blades," Wear, vol. 263, pp. 379-385, 2007.

[8] O. Bernard, G. Amiri, C. Haut, B. Feltz, A. M. Huntz, and M. Andrieux, "Mechanical and microstructural characterisation of oxide films damage," Materials Science and Engineering A, vol. 335, no. 1-2, pp. 32-42, 2002.

[9] J. M. West, Basic Corrosion and Oxidation, Ellis Horwood, New York, NY, USA, 2nd edition, 1986.

[10] Y. I. Oka, Y. Mukai, and T. Tsumura, "Mechanical properties and adhesion of oxide films examined by a solid particle impact method at high temperature corrosive environments," Wear, vol. 258, pp. 92-99, 2005. 
[11] Y. I. Oka, T. Yamabe, and T. Tsumura, "Exfoliation and fracture behavior of oxide films formed on titanium and its alloy in high temperature environments," Materials Science Forum, vol. 522-523, pp. 417-424, 2006.

[12] I. M. Hutchings, "The behaviour of metals under ballistic impact at sub-ordnance velocities," in Material Behavior under High Stress and Ultrahigh Loading Rates, J. Mescall and V. Weiss, Eds., vol. 29, p. 161, Proceedings of the Sagamore Army Materials Research Conference, 1983.

[13] Y. I. Oka, M. Matsumura, and T. Kawabata, "Relationship between surface hardness and erosion damage caused by solid particle impact," Wear, vol. 162-164, pp. 688-695, 1993.

[14] D. Tabor, The Hardness of Metals, Clarendon Press, Oxford, UK, 1951. 

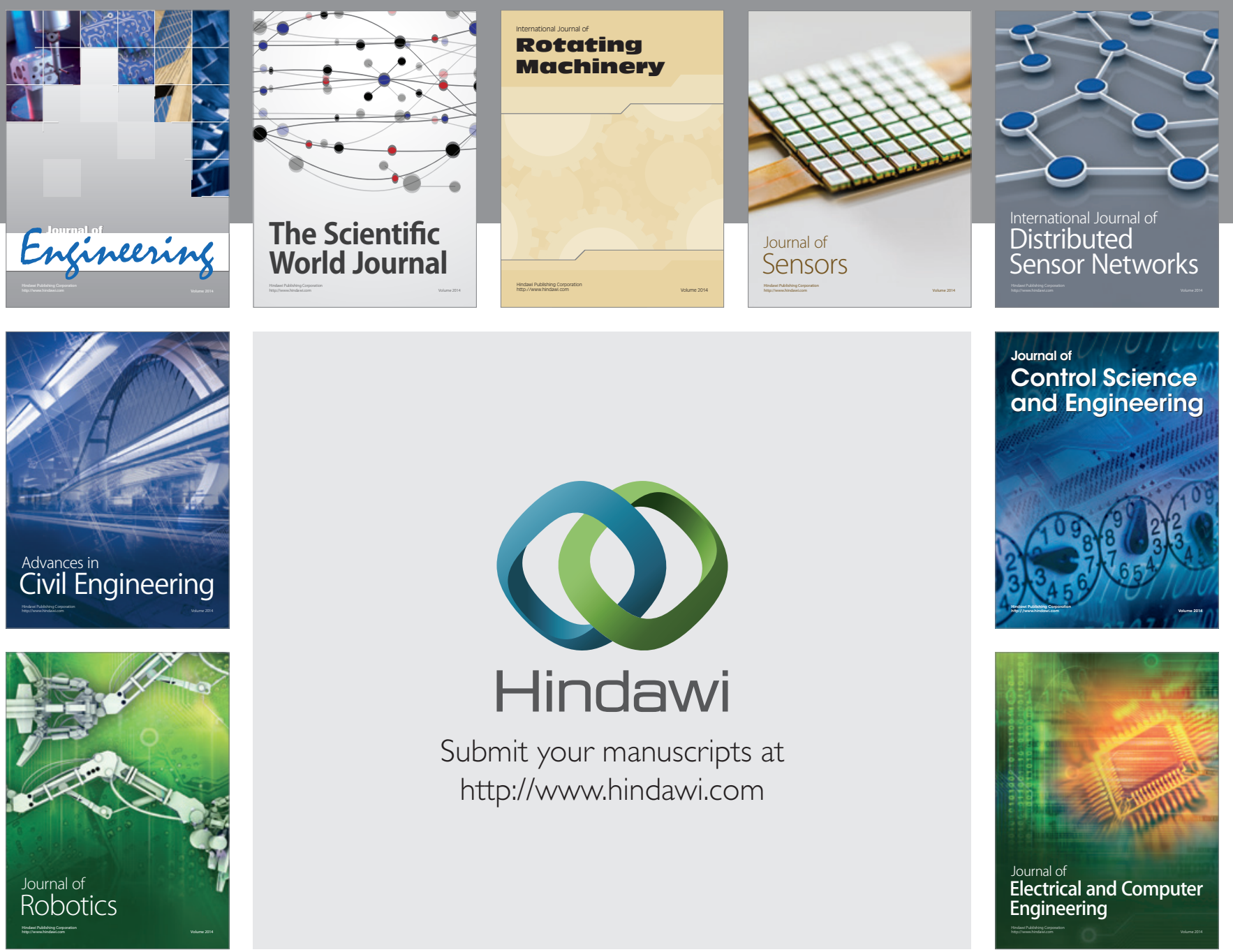

Submit your manuscripts at

http://www.hindawi.com
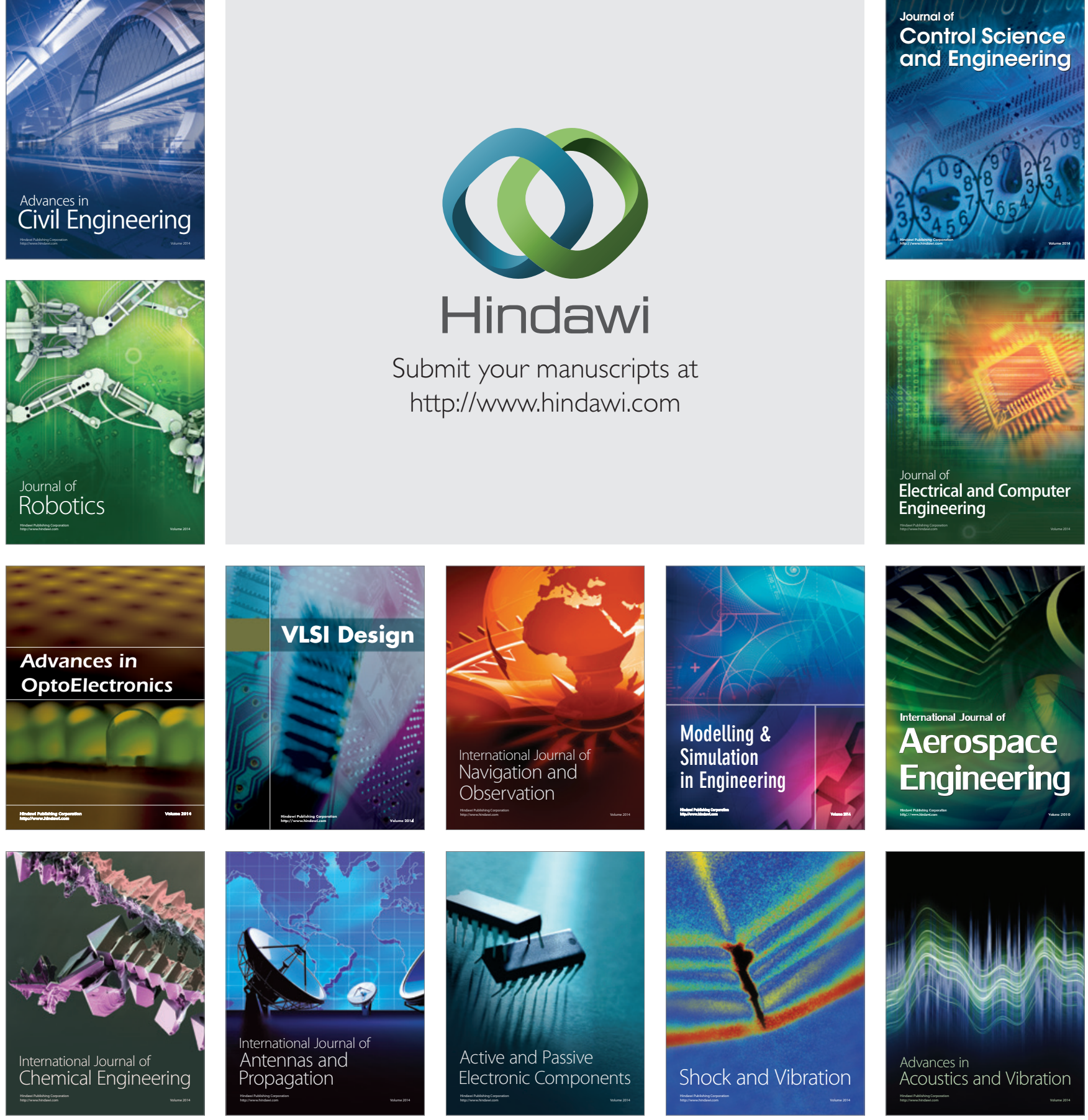